Factors influencing nurses' engagement with continuing professional development activities: A systematic review.

Juliette K Walter Clinical Practice Facilitator

Addenbrooke's Hospital

Cambridge

[Corresponding author]

Louise M Terry Associate Professor and Reader in Law and Ethics School of Health and Social Care, London South Bank University, London, SE1 OAA, UK. 
Abstract

Background

Continuing professional development is necessary for nurse registration and development. Understanding the factors influencing engagement may enhance CPD uptake.

Review Question: What factors influence hospital-based nurses' engagement with CPD activities in the UK?

Design

Systematic review incorporating narrative synthesis.

Data Sources

Database searches for published and grey literature from January 1995 to November 2018 were conducted via EBSCO Discovery Service, the British Nursing Index and the British Library.

\section{Review Methods}

An approved systematic review protocol was followed with studies then assessed against strict inclusion and exclusion criteria. Included studies were critically appraised, data extracted and a narrative synthesis conducted.

\section{Findings}

Five studies were reviewed. Four themes emerged: nurses' individual resources, their professional motivation, organisational commitment to learning and development, and managerial support. 


\section{Conclusion}

Factors influencing nurses' engagement with activities are multifaceted and interwoven. A question-based checklist to facilitate discussions between nurses and educators, managers or appraisers is presented.

\section{Keywords}

Continuing education; continuing professional development; nursing; nursing education; post registration education; systematic review.

\section{Key points}

Nurses must respond to increasingly complex patient needs, demonstrate critical thinking and evidence-based decisions whilst delivering efficient, compassionate care. Post-registration continuing professional development enables nurses to question care, provide quality care and develop extended skills.

Nurses cite insufficient developmental opportunities as a top reason for leaving jobs or the profession.

Insufficient organisational or managerial support may prevent nurses accessing CPD. Not all nurses are willing, or able, to use their own time or money for CPD.

Educators can facilitate CPD for individuals and organisations thereby safeguarding care standards.

\section{Reflective questions}

What CPD activity could enhance patient care in your practice?

Does the activity suit your learning style, work-life balance and personal commitments? How could you negotiate time or financial support with your manager, considering personal and organisational resources? 
Introduction

Nurses represent the largest proportion of healthcare professionals (Haddad and Toney-Butler, 2019). Regulatory bodies influence nurse education, set standards and seek to advance the profession, whilst striving to ensure care is well-informed, personcentred and compassionate (American Nurses Association, 2015; Health Education England (HEE), 2015; Nursing and Midwifery Board of Australia (NMBA), 2018; Nursing and Midwifery Council (NMC), 2018a). Wong et al's (2015) analysis of World Health Organization documents identified nursing education as a global concern and acknowledged that better post-registration continuing professional development (CPD) education enables nurses to question care, provide quality care and develop extended skills.

Since 1995, CPD has been mandatory for UK nurses (Beaumont and Stainton, 2016). Governments, employers and regulators expect nurses to keep themselves up-to-date (HEE, 2015; NMC, 2017; NMBA, 2018). 'Revalidation' requires nurses to undertake a minimum of 35 hours CPD relevant to their scope of practice over three years to maintain registration (NMC, 2019). Internationally, numerous activities are available (Hughes and Quinn, 2013; Bungeroth et al, 2018). Local identification of activities is encouraged with precise requirements varying (Wong et al, 2015; NMBA, 2016; NMC, 2017).

A dichotomy exists between expectation and practice. Nurses struggle to complete CPD in the face of workforce pressures (Keogh, 2014; Glasper, 2018; Bungeroth et al, 2018). Some identify expectations from managers to utilise personal time for CPD (Jones-Berry, 2016). Schweitzer and Krassa's (2010) integrative review identified the most frequent deterrents as cost, time and personal responsibility. Whilst CPD is an individual's responsibility, employers often influence accessibility (Bungeroth et al, 2018). Although there are often no legal requirements for employers to facilitate CPD 
(Beaumont and Stainton, 2016; NMC, 2019), many UK hospitals recognise governance and CPD are inextricably linked (Wood, 2006).

Deeper comprehension of factors influencing CPD engagement may enable educators to advocate and facilitate post-registration CPD more effectively (Frankel, 2009; Hughes and Quinn, 2013; Jones et al, 2015). To increase understanding, a systematic review was undertaken and formed part of a MA Practice Education. The review question was: "What factors influence hospital-based nurses' engagement with CPD activities in the UK?"

\section{Methodology}

The Cochrane and Preferred Reporting Items for Systematic Reviews and MetaAnalyses (PRISMA) guidelines informed processes (Liberati et al, 2009).

Population, Exposure and Outcomes (PEO) informed research question formulation and search terminology. Predefined database terminology, consideration of synonyms, abbreviations, truncation and Boolean operators enhanced searches. Four groups of terms were utilised, adjusted to fit individual databases: 1) nurse AND (England OR Scotland OR Wales OR "Northern Ireland" OR UK OR "United Kingdom" OR Britain OR "Great Britain"); 2) "continuing professional development" OR CPD OR "continuing education" OR "continuing personal and professional development" OR CPPD; 3) attitude OR belief OR opinion OR view OR perception OR perspective OR experience OR engagement; 4) questionnaire OR interview OR observation OR survey OR "focus group". Librarians advocated use of country and study type within searches.

Published and grey literature were searched via EBSCO Discovery Service and the British Nursing Index in November 2018 and the British Library EThOS database in January 2019. Google Scholar facilitated citation chaining and retrieval of full texts. Manual searching of reference lists of included studies occurred. A comparative 
CINAHL search was requested via the Royal College of Nursing.

Primary UK-based research considering attitudes, beliefs, opinions, views, perceptions, perspectives, experiences or engagement of hospital-based nurses with CPD was included. As UK CPD requirements were introduced in 1995 (Beaumont and Stainton, 2016), the timeframe was January 1995 to November 2018. Studies were excluded if the profession or workplace was unclear; nurses were not the respondents, or data were inseparable from non-nurses or non-hospital-based nurses in the study.

Searches yielded 769 papers (209 duplicates were automatically removed by EBSCO). Manual cross-checking excluded 141 additional duplicates. 419 papers were evaluated against the inclusion criteria by title then abstract and 76 full texts reviewed. Five returns required confirmation of participant workplaces. Author clarification was sought, resulting in one inclusion and four exclusions. Five further returns related to one study. Two published papers and a thesis were retained. Two conference papers were unobtainable. Five studies were identified for review. Figure 1 illustrates the search process.

A condensed version of the 'Reader's guide to the Literature on Interventions Addressing the Need for education and Training' (ReLIANT) and the 'Mixed Methods Appraisal Tool' (MMAT) (Koufogiannakis et al, 2005; Hong et al, 2018) were combined into a standardised, piloted form used to critique the studies (table 1). No studies were excluded.

Bibliographic information, research questions, aims, population, sample recruitment and demographics, data collection and analysis, results or themes were recorded (table 2). 
Narrative synthesis enabled elucidation of themes and formulation of areas for future investigation (Centre for Reviews and Dissemination, 2009). Qualitative, diagrammatical and tabulated data were reviewed. Congruency between findings was considered. Original data were retained to enhance synthesis. Tabulating textual data enabled open coding and higher-order heading formation, facilitating preliminary synthesis through an iterative, inductive process. As themes evolved, interrogation facilitated exploration of relationships.

Explicit, reproducible, comprehensive strategies were followed. Since the review was conducted as part of a Master's pathway, predominantly independent processes were required which could introduce bias, subjectivity and decrease credibility (BettanySaltikov and McSherry, 2016) so mitigating strategies were implemented. The protocol, including piloted quality appraisal and data extraction forms, was approved by the University Systematic Review Board. Academic librarians endorsed searches and an independent search provided comparison (Cooke et al, 2012). An experienced supervisor advised on processes and conducted independent appraisal and extraction of one study for comparison (Cooke et al, 2012).

Findings

All except Tame's (2009) doctoral thesis were published. All produced qualitative data. In the largest study reviewed producing two reports, Gould et al (2007) and Drey et al (2009) employed a questionnaire distributed across several hospitals. Remaining studies utilised face-to-face techniques (interviews and/or focus groups) within one hospital. The quality appraisal revealed that only Bahn (2007a, 2007b) had a clear research question and only Tame (2009) provided a clear explanation of method. None described their population in detail.

Most recruited a cross-section of nurses although Tame (2009) focused on peri- 
operative nurses. Balls (2010) recruited 'newly-qualified' nurses however participants may have been qualified for up to three years and the gender ratio (3 male: 3 female) seems unrepresentative of the workforce. Another study produced two publications: Bahn (2007a) exploring interview data, Bahn (2007b) focus groups. It was unclear whether any participants contributed to both. Further information may be found within table 2.

Forty-two findings were aggregated into thirty-five categories then synthesised into four over-arching themes: individual resources, nurses' professional motivation, organisational commitment to learning and development and managerial support (table 3). Transparent consideration of GRADE-CERQual facilitated confidence in the synthesised findings (table 4) (Lewin et al, 2018).

Individual resources

Funding influenced engagement. Some nurses were unsure how CPD was funded (Balls, 2010). Many expressed anger at being expected to source grants, or self-fund, and considered this a barrier (Bahn, 2007a; Tame, 2009; Balls, 2010). Some recognised managers and organisations were limited by financial constraints (Hogston,1995).

Nurses criticised expectations of using personal time, including holidays, particularly when CPD was primarily to enhance service delivery (Bahn, 2007a; Gould et al, 2007; Tame, 2009; Balls, 2010). Personal time included travel, attending activities, completing assignments and coordinating childcare (Gould et al, 2007; Tame, 2009). Compromises regarding time and funding were made, including negotiating shift patterns (Tame, 2009; Balls, 2010). Time and funding had the largest impact on worklife balance (Gould et al, 2007; Tame, 2009). Family support often made the difference between accessing, completing or withdrawing from CPD (Bahn, 2007b; Tame, 2009). 
Guilt was expressed as nurses and their families made sacrifices and redefined roles (Tame, 2009). Others rejected such personal sacrifices arguing they already worked in underpaid, severely-stretched systems with few guarantees of promotion or financial gain from CPD (Bahn, 2007a; Tame, 2009).

All studies identified CPD affected self-confidence and self-worth. Three studies identified appraisals and personal development plans (PDPs) as supporting engagement (Bahn, 2007a; Tame, 2009; Balls, 2010). In all studies, participants discussed the importance of individualised CPD. This applied to content, mode-ofdelivery and the potential to impact patient care (Hogston, 1995; Bahn, 2007b; Gould et al, 2007; Balls, 2010). Facilitating identification of activities, enabling congruence between individuals' resources, practice requirements and patient benefits, appraisals and PDPs also acted as a monitor regarding CPD uptake and parity (Bahn, 2007b; Tame, 2009; Balls, 2010). Whilst lack of appraisal or PDPs were noted in areas where engagement was low, some nurses sought CPD to gain feedback (Tame, 2009).

Some nurses worried they were falling behind due to changes in nurse education (Bahn, 2007a). Previous experiences of school, pre-registration or post-registration courses dissuaded some from higher education courses (Gould et al, 2007; Tame, 2009). University staff attitudes were influential on continued engagement (Bahn, 2007b; Tame, 2009).

Professional motivation

Participants in all studies were motivated to access CPD identifying it consolidated, maintained and updated skills, enabling professional progression and status, impacted competence and enhanced care (Hogston, 1995; Bahn, 2007a; Gould et al, 2007; Tame, 2009). The tenet of high-quality care is intrinsic to nursing professionalism (Bahn, 2007b). Hogston (1995) considered the relationship between CPD and care 
identifying that learning must occur, not simply attending activities. Whilst increased knowledge can improve standards (Bahn, 2007a; Tame, 2009), this may not follow when CPD is solely to fulfil registrational statutes. Some were motivated by CPD facilitating the evolution of extended roles (Bahn, 2007a; Gould et al, 2007; Tame, 2009). Nurses considered CPD facilitated legitimate questioning of care, enabling them to improve practice (Hogston, 1995; Bahn, 2007b; Tame, 2009).

Organisational commitment to learning and development Some organisations influence CPD by making it mandatory. Some nurses believed this ensured nurse and patient safety whilst others considered it merely organisational protection (Bahn, 2007b; Gould et al, 2007). Organisational aspects such as low staffing led to CPD omission, the implications of which were not fully appreciated (Bahn, 2007b; Drey et al, 2009).

Nurses working in organisations where CPD was not valued expressed reduced confidence, increased anxiety, secret study and horizonal violence (Balls, 2010; Tame, $2011,2012)$. Where learning and development was embedded, with staff enabled to disseminate learning and implement changes, care standards and working relationships appeared enhanced (Hogston, 1995; Bahn, 2007a; Gould et al, 2007; Tame, 2009).

Nurses identified staffing levels affected non-mandatory CPD more, with organisations unable to free staff to attend (Bahn, 2007a; Gould et al, 2007; Tame, 2009). Reduced funding to back-fill staff or pay for CPD, was identified (Bahn, 2007a; Gould et al, 2007; Tame, 2009; Balls, 2010). Transferrable skills were highlighted as potentially encouraging organisations to support non-mandatory CPD (Bahn, 2007b).

Increased awareness of CPD influenced engagement, although resentment ensued if it 
was inaccessible (Gould et al, 2007; Balls, 2010). There was disparity within and across organisations (Bahn, 2007a; Gould et al, 2007; Tame, 2009; Balls, 2010). Tame (2011) identified managers sabotaging nurses' attempts to study through 'fixing' rotas or restricting study time. Part-time working, shift-patterns, career stage and age were discussed as potentially preventing CPD (Bahn, 2007b; Gould et al, 2007; Tame, 2009). Seeing nurses 'earmarked' for progression and being offered more CPD, or conversely refusing to engage, were highlighted as unfair (Hogston, 1995; Tame, 2009, 2012). Nurses believed staff retention was facilitated by organisations encouraging CPD whilst the converse was also true (Gould et al, 2007; Drey et al, 2009; Tame, 2009; Balls, 2010).

\section{Managerial support}

Whilst organisations influence CPD, managers were described as pivotal in influencing 'cultural milieu' (Tame, 2012). The value managers placed on CPD dictated how much and what was accessed by individuals (Hogston, 1995; Bahn, 2007a, 2007b; Gould et al, 2007; Tame, 2009). Managers who engaged with CPD, fostering positive environments for learning, dissemination of knowledge and reviewing practice, were viewed as good managers (Bahn, 2007a; Gould et al, 2007; Tame, 2009). Nurses receiving managerial support felt encouraged and valued as a professional, perceiving managerial confidence in their abilities (Hogston, 1995; Tame, 2009). Others identified managers as feeling threatened or jealous of junior nurses accessing CPD (Gould et al, 2007; Tame, 2009).

Nurses understood staffing levels and funding were often beyond managerial control (Tame, 2009). Some believed that if CPD relevance was apparent, managers were more likely to support funding and staff release (Hogston, 1995; Bahn, 2007a). Implicit, and explicit, was the potential for using CPD as a reward or sanction, to motivate or enhance performance (Hogston, 1995; Gould et al, 2007; Drey et al, 2009). 
Lack of managerial engagement caused frustration (Hogston, 1995; Gould et al, 2007; Tame, 2009; Balls, 2010). Nurses remained determined to develop in the face of managerial resistance and might avoid approaching these managers or disclosing their CPD (Bahn, 2007b; Tame, 2009). Others felt pressured into CPD by managers fulfilling organisational requirements (Gould et al, 2007; Tame, 2009).

\section{Discussion}

Healthcare, nursing roles, and professional requirements have metamorphosed during the time of these studies. Nurses must respond to increasingly complex patient needs, demonstrate critical thinking and evidence-based decisions whilst delivering efficient, compassionate care (HEE, 2015; Irwin et al, 2018; NHS, 2019). All studies confirmed nurses' awareness of professional requirements to facilitate care through maintaining and updating skills (Glasper, 2018). Nurses must be empowered to access CPD (Mazhindu, 2014).

Nurses' professional motivation was threatened when CPD engagement was thwarted. Insufficient organisational or managerial support, or disparity, means nurses struggling to balance personal resources against professional demands. Organisational austerity affects CPD and expecting nurses to utilise personal resources is a concerning trend (Shaw, 2012; Glasper, 2015; Jones-Berry, 2016; Parliament House of Commons, 2018). Nurses are spending personal time and money on CPD (Keogh, 2014; JonesBerry, 2016; Glasper, 2018). Personal sacrifices are considerable, particularly for those with families (Dowswell et al, 2000; Ellis and Nolan, 2005). Nurses struggle to maintain an acceptable work-life balance, citing insufficient developmental opportunities as the top reason for leaving (Jones-Berry, 2016; NHS, 2019). Some feel bullied into CPD; Tame's $(2011,2012)$ emotional language of 'horizontal violence' highlights this. Discord impacts retention within organisations and the profession (Hasselhorn et al, 2003). 
Bungeroth et al (2018) and Glasper (2018) emphasise CPD is a basic requirement, with reduced resources potentially preventing nurses from re-registering (Parliament House of Commons, 2018). Reduced workforces, or nurses whose practice is outdated, may have far-reaching consequences as they train the next generation (Glasper, 2018). CPD should be viewed as an investment, increasing retention amidst global concerns regarding nursing shortfalls (Health Workforce Australia, 2014; Wong et al, 2015; Haddad and Toney-Butler, 2019; NHS, 2019).

Whilst managers and organisations must govern activities, their approach is crucial (Ellis and Nolan, 2005; Hughes, 2005; Wong et al, 2015) as they influence the largest employee group (Glasper, 2018; Haddad and Toney-Butler, 2019; NHS, 2019). They must recognise that as nursing transforms, so do individual career trajectories (Pool et al, 2015). This is particularly relevant in a predominantly-female profession where many require flexible shift patterns, fitting with personal responsibilities (Haddad and Toney-Butler, 2019; NHS, 2019). No nurse should believe their development is considered insignificant (Hasselhorn et al, 2003; NHS, 2019). Attempts to mitigate barriers must be considered (Brook et al, 2019).

Role extension and revisions to UK nurse education affect CPD (Wong et al, 2015; Kristjánsson et al, 2017; Irwin et al, 2018). New nurses require revised support and development (Quek and Shorey, 2018; Brook et al, 2019). Imminent pre-registration amendments necessitate further CPD evaluation (NMC, 2018b). Mazhindu (2014) identified nurses with extended roles still struggle to receive suitable CPD as found in this review (Gould et al, 2007). Collaboration between universities may facilitate opportunities for both groups (Kristjánsson et al, 2017; Gray et al, 2018). 
Employers' support cannot be underestimated (Jones-Berry, 2016). Maintenance and development of professional roles through CPD is acknowledged by many UK organisations, with professional bodies desiring their support (HEE, 2015; Bungeroth et al, 2018). As more nurses undertake primary research, CPD that improves the quality of research reporting could be valuable given the weaknesses identified in Table 1. This review shows nurses' professional motivation incorporated a desire to improve patient safety and enhance care. CPD engagement is essential to this with potential to transform workplace cultures (Bjørk et al, 2009; Shaw, 2012; Zander et al, 2016; NHS, 2019). Leadership influences extend to facilitating or preventing implementation of learning from CPD, potentially inhibiting contemporary, evidence-based practices (Jones-Berry, 2016; NHS, 2019). Organisational or managerial disengagement may affect organisational ranking. The UK's Care Quality Commission (2019) considers evidence substantiating that staff receive appraisal of learning needs, adequate support and training to deliver safe, effective care.

Limitations

Incomplete reporting resulted in inability to confirm participant workplaces. Failure to successfully contact authors resulted in study exclusion.

Despite aiming to review studies from across the UK, only studies based in England were retrieved. The absence of exploration from across the wider UK may affect findings.

\section{Conclusion}

Bahn (2007b) identified three essential components to effective health care delivery: employer, nurse, and patient. Forming the bulk of healthcare workforces, nurses are vital (Haddad and Toney-Butler, 2019). Throughout forty-year careers, CPD must be facilitated (Bjørk et al, 2009; Pool et al, 2015; NMC, 2018a). As pre-registration 
education transforms, and patient acuity increases, so must CPD, enabling continuous development of competent, highly skilled practitioners (Irwin et al, 2018; NMC, 2018b; Quek and Shorey, 2018).

Nurses recognise that CPD impacts professional status and competence. This review identified factors influencing CPD engagement as nurses' individual resources, professional motivation, organisational commitment to learning and development and managerial support. Organisations and managers must commit to supporting CPD. The value of nurses' CPD must be elevated by professional bodies, governments and global organisations. The consequences of decreased development or depleted workforces affects healthcare for everyone.

Educators can facilitate CPD for individuals and organisations thereby safeguarding care standards (Smith, 2009; Sykes et al, 2014). They could coordinate organisational and managerial support which this review identified nurses find invaluable. To aid discussions, a checklist has been developed (figure 2) which could be utilised by individual nurses, managers and appraisers. Central to discussions is the need to ensure individuals meet professional requirements. Although the influence of each factor (figure 3) will vary, individuals should evaluate these. Appropriate CPD engagement will maintain and develop practice, benefitting the organisation and patients.

To support this, the review recommends:

- For individuals: appraisal of own CPD requirements; willingness to negotiate with managers; accepting the need to invest personal time and finances, aiding career development; maintaining a healthy work-life-study balance;

- For educators, managers and organisations: collaboration to create individualised practice and career development strategies; consideration that 
shifts impact CPD; making CPD relevant, visible and achievable, acknowledging professional requirements and safeguarding care;

- For researchers: investigate CPD provision and the needs of nurses fulfilling extended roles.

References

American Nurses Association. Nursing: scope and standards of practice, 3rd ed. 2015. http://www.ovid.com/site/catalog/books/8277.jsp\#horizontalTab2 (accessed 10 May 2019)

Bahn D. Orientation of nurses towards formal and informal learning: motives and perceptions. Nurse Educ Today. 2007a;27(7):723-730.

https://doi.org/10.1016/j.nedt.2006.10.006

Bahn D. Reasons for post registration learning: impact of the learning experience. Nurse Educ Today. 2007b;27(7):715-722. https://doi.org/10.1016/j.nedt.2006.10.005

Balls P. What are the factors that affect band 5 nurses' career development and progression? Nurs Times. 2010;106(15):10-13

Beaumont C, Stainton R. RCN Factsheet: Continuing Professional Development (CPD) for nurses working in the United Kingdom (UK). 2016. https://www.rcn.org.uk/aboutus/policy-briefings/pol-1614 (accessed 10 May 2019)

Bettany-Saltikov JA, McSherry R. How to do a systematic literature review in nursing: a step-by-step guide. 2nd ed. London: McGraw-Hill; 2016 
Bjørk IT, Tørstad S, Hansen BS, Samdal GB. Estimating the cost of professional developmental activities in health organizations. Nurs Econ. 2009;27(4):239-244

Brook J, Aitken L, Webb R, MacLaren J, Salmon D. Characteristics of successful interventions to reduce turnover and increase retention of early career nurses: a systematic review. Int J Nurs Stud. 2019;91:47-59.

https://doi.org/10.1016/j.jnurstu.2018.11.003

Bungeroth L, Fennell E, Aiken S. Investing in a safe and effective workforce.

Continuing professional development for nurses in the UK.

2018. https://www.rcn.org.uk/professional-development/publications/pdf-007028 (accessed 10 May 2019)

Care Quality Commission. Staff skills and knowledge. 2019.

https://www.cqc.org.uk/guidance-providers/healthcare/staff-skills-knowledgehealthcare-services (accessed 10 May 2019)

Centre for Reviews and Dissemination. Systematic reviews: CRD's guidance for undertaking reviews in healthcare. 2009. http://www.york.ac.uk/crd/guidance (accessed 10 May 2019)

Cooke A, Smith D, Booth A. Beyond PICO: the SPIDER tool for qualitative evidence synthesis. Qual Health Res. 2012;22(10):1435-1443.

https://doi.org/10.1177/1049732312452938

Dowswell T, Bradshaw G, Hewison J. Child care responsibilities and participation in continuing education and training: issues relating to motivation, funding and domestic 
roles. J Adv Nurs. 2000;32(2):445-453. https://doi.org/10.1046/j.1365-

\section{$2648.2000 .01495 . x$}

Drey N, Gould D, Allan T. The relationship between continuing professional education and commitment to nursing. Nurse Educ Today. 2009;29(7):740-745. https://doi.org/10.1016/j.nedt.2009.03.008

Ellis L, Nolan M. Illuminating continuing professional education: unpacking the black box. Int J Nurs Stud. 2005;42(1):97-106. https://doi.org/10.1016/j.ijnurstu.2004.05.006 Frankel A. Nurses' learning styles: promoting better integration of theory into practice. Nurs Times. 2009;105(2):24-27.

Glasper A. Is essential learning being compromised by austerity? $\mathrm{Br} \mathrm{J}$ Nurs. 2015;24(11):602-603. https://doi.org/10.12968/bjon.2015.24.11.602

Glasper A. Problems affecting the continuing professional development of nurses. $\mathrm{Br} \mathrm{J}$ Nurs. 2018;27(12):714-715. https://doi.org/10.12968/bjon.2018.27.12.714

Gould D, Drey N, Berridge E. Nurses' experiences of continuing professional development. Nurse Educ Today. 2007;27(6):602-609.

https://doi.org/10.1016/j.nedt.2006.08.021

Gray K, Wilde R, Shutes K. Enhancing nurse satisfaction: an exploration of specialty nurse shortage in a region of NHS England. Nurs Manag. 2018;25(1):26-33. https://doi.org/10.7748/nm.2018.e1695 
Haddad LM, Toney-Butler TJ. StatPearls: Nursing shortage. 2019.

https://www.ncbi.nlm.nih.gov/books/NBK493175/ (accessed 10 May 2019)

Hasselhorn HM, Tackenberg P, Müller BH. (Eds). Working conditions and intent to leave the profession among nursing staff in Europe. 2003.

http://citeseerx.ist.psu.edu/viewdoc/download?doi=10.1.1.622.3322\&rep=rep1\&type $=p$

df (accessed 10 May 2019)

Health Education England. Raising the bar. Shape of caring: a review of the future of education and training of registered nurses and care assistants.

2015. https://www.hee.nhs.uk/our-work/shape-caring-review (accessed 10 May 2019)

Health Workforce Australia. Nursing workforce sustainability - improving nurse retention and productivity report. 2014.

www.health.gov.au/internet/main/publishing.nsf/Content/nursing-workforcesustainability-improving-nurse-retention-and-productivity (accessed 10 May 2019)

Hogston R. Nurses' perceptions of the impact of continuing professional education on the quality of nursing care. J Adv Nurs. 1995;22(3):586-593.

https://doi.org/10.1046/j.1365-2648.1995.22030586.x

Hong QN, Pluye P, Fàbregues S, Bartlett G, Boardman F, Cargo M, Dagenais P, Gagnon M-P, Griffiths F, Nicolau B, O'Cathain A, Rousseau M-C, Vedel I. Mixed Methods Appraisal Tool (MMAT), Version 2018. User Guide. 2018.

http://mixedmethodsappraisaltoolpublic.pbworks.com/w/file/fetch/127916259/MMAT_20

18_criteria-manual_2018-08-01_ENG.pdf (accessed 10 May 2019) 
Hughes E. Nurses' perceptions of continuing professional development. Nurs Stand. 2005;19(43):41-49. https://doi.org/10.7748/ns2005.07.19.43.41.c3904

Hughes SJ, Quinn FM. Quinn's principles and practice of nurse education. 6th ed. Cheltenham: Nelson Thornes; 2013

Irwin C, Bliss J, Poole K. Does preceptorship improve confidence and competence in newly qualified nurses: a systematic literature review. Nurse Educ Today. 2018;60:3546. https://doi.org/10.1016/j.nedt.2017.09.011

Jones K, Warren A, Davies A. Mind the gap: exploring the needs of early career nurses and midwives in the workplace. Birmingham and Solihull Local Education and Training Council, Birmingham. 2015. https://www.nhsemployers.org//media/Employers/Documents/Plan/Mind-the-Gap-Smaller.pdf (accessed 10 May 2019) Jones-Berry S. Nurses may fall at revalidation's first hurdle without CPD support. Nurs Stand. 2016;30(31):12-3. https://doi.org/10.7748/ns.30.31.12.s13

Keogh K. Pressures at work forcing staff to complete PREP in their own time. Nurs Stand. 2014;28(31):9. https://doi.org/10.7748/ns2014.04.28.31.9.s2

Koufogiannakis D, Booth A, Brettle A. ReLIANT: Reader's guide to the Literature on Interventions Addressing the Need for education and Training. 2005. https://core.ac.uk/download/pdf/11880292.pdf (accessed 10 May 2019)

Kristjánsson K, Varghese J, Arthur J, Moller F, Ferkany M. Virtuous practice in nursing. Research report. Jubilee Centre for Character and Virtues, University of Birmingham. 
2017. https://www.jubileecentre.ac.uk/media/news/article/5530/-Virtuous-Practice-inNursing-Research-Report-Published (accessed 10 May 2019)

Lewin S, Bohren M, Rashidian A, Munthe-Kaas H, Glenton C, Colvin CJ, Garside R, Noyes J, Booth A, Tunçalp O, Wainwright M, Flottorp S, Tucker JD, Carlsen B. Applying GRADE-CERQual to qualitative evidence synthesis findings-paper 2: how to make an overall CERQual assessment of confidence and create a summary of qualitative findings table. Implement Sci. 2018;13(Suppl 1)10:11-23. https://doi.org/10.1186/s13012-017-0689-2

Liberati A, Altman DG, Tetzlaff J, Mulrow C, Gøtzsche PC, loannidis JPA, Clarke M, Devereaux PJ, Kleijnen J, Moher D. The PRISMA statement for reporting systematic reviews and meta-analyses of studies that evaluate healthcare interventions: explanation and elaboration. BMJ 2009;339:b2700. https://doi.org/10.1136/bmj.b2700

Mazhindu D. Shared responsibility. Nursing Manag UK. 2014;21(4):2. https://doi.org/10.7748/nm.21.4.12.s12

Moher D, Liberati A, Tetzlaff J, Altman DG. The PRISMA Group. Preferred Reporting Items for Systematic Reviews and Meta Analyses: the PRISMA statement. PLoS Medicine. 2009;6(7):e1000097. https://doi.org/10.1371/journal.pmed1000097

NHS. NHS long term plan. 2019. https://www.longtermplan.nhs.uk/ (accessed 10 May 2019) 
Nursing and Midwifery Board of Australia. Registration standard: continuing professional development. 2016.

https://www.nursingmidwiferyboard.gov.au/registration-standards/continuingprofessional-development.aspx (accessed 10 May 2019)

Nursing and Midwifery Board of Australia. Code of conduct for nurses. 2018. https://www.nursingmidwiferyboard.gov.au/Codes-Guidelines-Statements/Professionalstandards.aspx (accessed 10 May 2019)

Nursing and Midwifery Council. Revalidation. How to revalidate with the NMC: requirements for renewing your registration. 2017. https://www.nmc.org.uk/globalassets/sitedocuments/revalidation/how-to-revalidatebooklet.pdf (accessed 10 May 2019)

Nursing and Midwifery Council. The Code: Professional standards of practice and behaviour for nurses and midwives. 2018a.

https://www.nmc.org.uk/standards/code/read-the-code-online/ (accessed 10 May 2019)

Nursing and Midwifery Council. Future nurse: standards of proficiency for registered nurses. 2018b. https://www.nmc.org.uk/standards/standards-for-nurses/standards-ofproficiency-for-registered-nurses/ (accessed 10 May 2019)

Nursing and Midwifery Council. Revalidation. Employers' guide to revalidation. 2019. https://www.nmc.org.uk/globalassets/sitedocuments/revalidation/employers-guide-torevalidation.pdf (accessed 10 May 2019)

Parliament. House of Commons. Health Committee. The nursing workforce: second report of session 2017-19, [HC 2017-2019 353]. 2018. 
https://publications.parliament.uk/pa/cm201719/cmselect/cmhealth/353/353.pdf (accessed 10 May 2019)

Pool IA, Poell RF, Berings MGMC, ten Cate O. Strategies for continuing professional development among younger, middle-aged, and older nurses: a biographical approach. Int J Nurs Stud. 2015;52:939-950. https://doi.org/10.1016/j.jjnurstu.2015.02.004

Quek GJH, Shorey S. Perceptions, experiences, and needs of nursing preceptors and their preceptees on preceptorship: an integrative review. J Prof Nurs. 2018;34:417-428. https://doi.org/10.1016/j.profnurs.2018.05.003

Schweitzer DJ, Krassa TJ. Deterrents to nurses' participation in continuing professional development: an integrative literature review. J Contin Educ Nurs. 2010;41(10): 441447. https://doi.org/10.3928/00220124-20100601-05

Shaw T. Unravelling the consequence of practice development: an exploration of the experiences of healthcare practitioners. Int Pract Dev J. 2012;2(2)article 2:1-23. www.fons.org/library/journal/volume2-issue2/article2 (accessed 10 May 2019)

Smith A. Learning theories and their application. In: Smith, A., McAskill, H., Jack, K. (Eds), Developing advanced skills in practice teaching. Basingstoke: Palgrave Macmillan; 2009

Sykes C, Urquhart C, Foster A. Role of the practice education facilitator (PEF): the Cambridgeshire model underpinned by a literature review of educational facilitator roles. Nurse Educ Today. 2014;34(11):1395-1397.

https://doi.org/10.1016/j.nedt.2014.03.014 
Tame S. Secret study: a new concept in continuing professional education. Nurse Educ Today. 2011;31(5):482-487. https://doi.org/10.1016/j.nedt.2010.09.007

Tame S. The relationship between continuing professional education and horizontal violence in perioperative practice. J Perioper Pract. 2012;22(7):220-225. https://doi.org/10.1177/175045891202200702

Tame SL. Continuing professional education: the experiences and perceptions of nurses working in perioperative patient care. $\mathrm{PhD}$ thesis submitted to University of Hull, 2009. https://core.ac.uk/download/pdf/2731442.pdf (accessed 10 May 2019)

Wong FKY, Liu H, Wang $\mathrm{H}$, Anderson D, Seib C, Molasiotis A. Global nursing issues and development: analysis of World Health Organization documents. J Nurs Scholarsh. 2015;47(6):574-583. https://doi.org/10.1111/jnu.12174

Wood J. NT research. Exploring staff nurses' views on professional development. Nurs Times. 2006;102(13):36-38.

Zander B, Aiken LH, Busse R, Rafferty AM, Sermeus W, Bruyneel L. The state of nursing in the European Union. Eurohealth. 22(1):3-6. 2016.

http://www.euro.who.int/_data/assets/pdf_file/0004/304393/EuroHealth_v22n1.pdf (accessed 10 May 2019) 
Figure 1: Study selection process. (Moher et al, 2009)

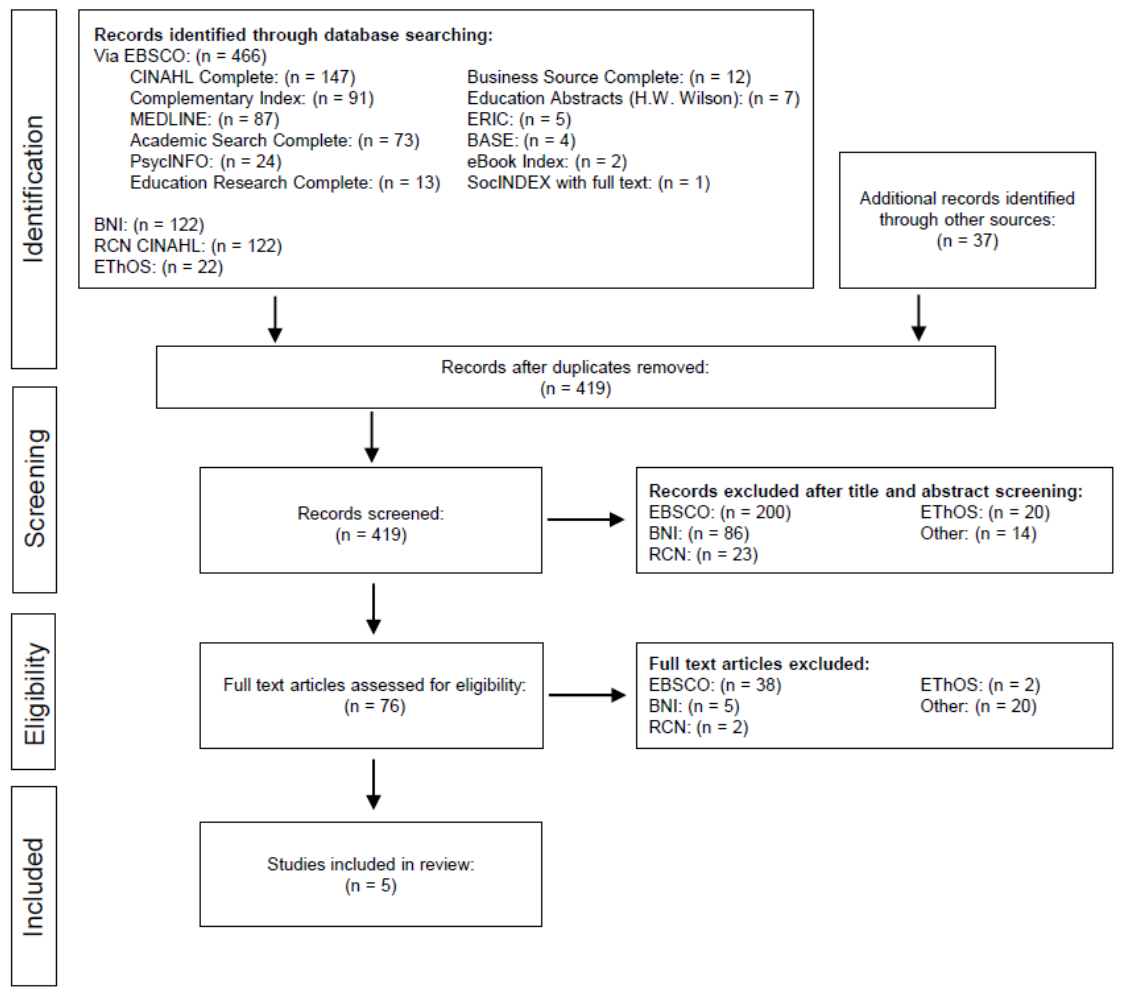


Figure 2: Checklist to aid CPD discussions between the individual and educator, manger or appraiser.

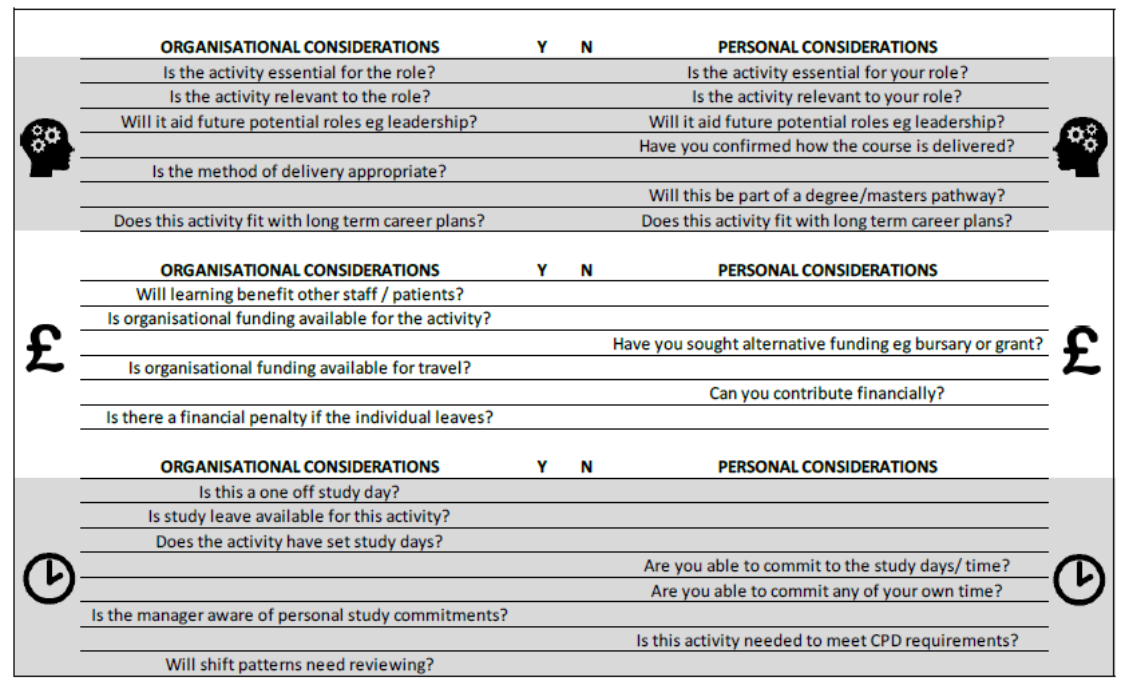


Figure 3: Factors for consideration to ensure CPD engagement

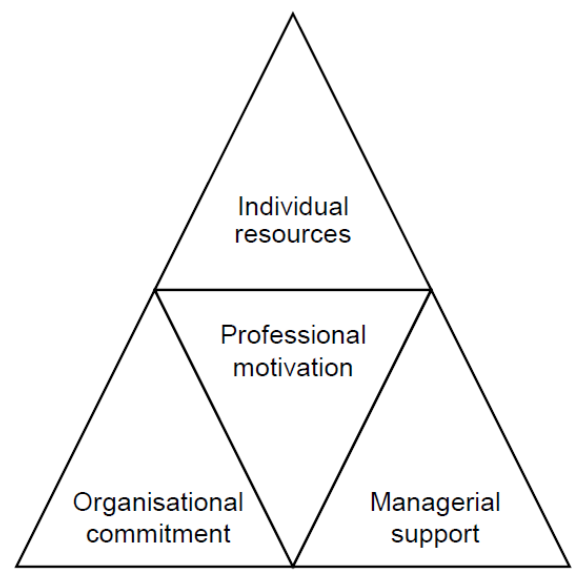


Table 1: Quality appraisal of studies

\begin{tabular}{|c|c|c|c|c|c|}
\hline & $\begin{array}{l}\text { Bahn } \\
(2007 a) \\
(2007 b)\end{array}$ & $\begin{array}{l}\text { Balls } \\
(2010)\end{array}$ & $\begin{array}{c}\text { Gould et } \\
\text { al (2007) / } \\
\text { Drey et al } \\
(2009)\end{array}$ & $\begin{array}{l}\text { Hogston } \\
\text { (1995) }\end{array}$ & $\begin{array}{l}\text { Tame } \\
\text { (2009) } \\
(2011) \\
(2012)\end{array}$ \\
\hline Peer reviewed? & $\checkmark$ & $\checkmark$ & $\checkmark$ & $?$ & $\checkmark^{*}$ \\
\hline Are there clear research questions? & $\checkmark$ & $X$ & $X$ & $x$ & $X$ \\
\hline $\begin{array}{l}\text { Do the collected data allow to address the } \\
\text { research questions? }\end{array}$ & $\checkmark$ & $\checkmark$ & $\checkmark$ & $\checkmark$ & $\checkmark$ \\
\hline Is the objective of the study clearly stated? & $x$ & $x$ & $x$ & $x$ & $x$ \\
\hline Is the reason for the study apparent? & $\checkmark$ & $\checkmark$ & $\checkmark$ & $\checkmark$ & $\checkmark$ \\
\hline Is the population described in detail? & $x$ & $\mathrm{x}$ & $x$ & $x$ & $\mathrm{x}$ \\
\hline Is the number of study participants clearly stated? & $\checkmark$ & $\checkmark$ & $\checkmark$ & $\checkmark$ & $\checkmark$ \\
\hline Is there a description of participants? & $x$ & $x$ & $\checkmark$ & $x$ & $\checkmark$ \\
\hline Is the loss of any participants explained? & $x$ & $\mathrm{x}$ & $\mathrm{x}$ & $\checkmark$ & $\checkmark$ \\
\hline Is participation voluntary? & $\checkmark$ & $\checkmark$ & $\checkmark$ & $\checkmark$ & $\checkmark$ \\
\hline Was the research method clearly stated? & $x$ & $\mathrm{x}$ & $x$ & $x$ & $\checkmark$ \\
\hline Is it appropriate for the question being asked? & $\checkmark$ & $\checkmark$ & $\checkmark$ & $\checkmark$ & $\checkmark$ \\
\hline $\begin{array}{l}\text { Is the qualitative approach appropriate to answer } \\
\text { the research question? }\end{array}$ & $\checkmark$ & $\checkmark$ & $\checkmark$ & $\checkmark$ & $\checkmark$ \\
\hline $\begin{array}{l}\text { Are the qualitative data collection methods } \\
\text { adequate to address the research question? }\end{array}$ & $\checkmark$ & $\checkmark$ & $\checkmark$ & $\checkmark$ & $\checkmark$ \\
\hline Are the findings adequately derived from the data? & $\checkmark$ & $\checkmark$ & $\checkmark$ & $\checkmark$ & $\checkmark$ \\
\hline $\begin{array}{l}\text { Is the interpretation of results sufficiently } \\
\text { substantiated by the data? }\end{array}$ & $\checkmark$ & $\checkmark$ & $x$ & $\checkmark$ & $\checkmark$ \\
\hline $\begin{array}{l}\text { Is there coherence between qualitative data } \\
\text { sources, collection, analysis and interpretation? }\end{array}$ & $\checkmark$ & $\checkmark$ & $\checkmark$ & $\checkmark$ & $\checkmark$ \\
\hline
\end{tabular}

Legend: ' $\checkmark$ ' Yes; 'X' No; '?' Can't tell

Footnotes: Table adapted from 'ReLIANT' and 'Mixed Methods Appraisal Tool'

(Koufogiannakis et al, 2005; Hong et al, 2018).

* Study 5 contains two published articles alongside a thesis which is not peer reviewed. 


\begin{tabular}{|c|c|c|c|c|c|c|}
\hline Study & Aims & Study design & $\begin{array}{l}\text { Setting and } \\
\text { Population }\end{array}$ & $\begin{array}{l}\text { Sample \& data } \\
\text { collection }\end{array}$ & Themes / findings & Strengths / limitations \\
\hline $\begin{array}{l}\text { Bahn } \\
(2007 a) \\
(2007 b)\end{array}$ & $\begin{array}{l}\text { To gain information } \\
\text { on the current } \\
\text { orientation of } \\
\text { registered nurses } \\
\text { towards continuing } \\
\text { education and } \\
\text { lifelong learning } \\
\text { Reasons and } \\
\text { motives for } \\
\text { participation; } \\
\text { influencing factors; } \\
\text { views and } \\
\text { perceptions of } \\
\text { experiences meeting } \\
\text { needs and } \\
\text { expectations }\end{array}$ & $\begin{array}{l}\text { Qualitative } \\
\text { empirical }\end{array}$ & $\begin{array}{l}\text { Not stated } \\
\text { [author contacted] } \\
\text { Hospital based, } \\
\text { England } \\
\text { Nurses employed } \\
\text { in public and } \\
\text { private clinical } \\
\text { settings; who have } \\
\text { or are currently } \\
\text { taking part in } \\
\text { continuing } \\
\text { education }\end{array}$ & $\begin{array}{l}\text { Randomly } \\
\text { selected } \\
\text { candidates } \\
20 \text { semi- } \\
\text { structured one-to- } \\
\text { one interviews } \\
25 \text { registered } \\
\text { nurses; three } \\
\text { focus group } \\
\text { interviews }\end{array}$ & $\begin{array}{l}\text { The learning experience; } \\
\text { Attitudes to learning; Impact of } \\
\text { the learning experience; } \\
\text { Factors perceived to affect } \\
\text { learning }\end{array}$ & $\begin{array}{l}\text { - Single author/researcher } \\
\text { - Ethical approval } \\
\text { - Setting and population unclear [email } \\
\text { clarification] } \\
\text { - Part of larger study } \\
\text { - Unclear why not all } 25 \text { interviewed or if } \\
\text { some did interviews and focus groups } \\
\text { - Unclear time lag between interview and } \\
\text { focus groups } \\
\text { - Minimal demographics; implies done but not } \\
\text { published } \\
\text { - Useful interview and focus group topic } \\
\text { guides } \\
\text { - Quotes used but not linked to participants } \\
\text { - Sindings not all under 'themes' }\end{array}$ \\
\hline $\begin{array}{l}\text { Balls } \\
(2010)\end{array}$ & $\begin{array}{l}\text { To explore the } \\
\text { perceptions of band } \\
5 \text { nurses and the } \\
\text { factors that affect } \\
\text { their development } \\
\text { and ability to change } \\
\text { posts in a large acute } \\
\text { Trust }\end{array}$ & $\begin{array}{l}\text { Interpretive / } \\
\text { hermeneutic } \\
\text { phenomenology }\end{array}$ & $\begin{array}{l}\text { Large acute trust, } \\
\text { England } \\
\\
\text { Newly qualified } \\
\text { nurses; diploma or } \\
\text { degree qualified; } \\
\text { recruited between } \\
\text { Sept } 2005 \text { - Sept } \\
2007 \text { under Agenda } \\
\text { for Change terms; } \\
\text { been in post for } \\
\text { minimum } 6 \text { months }\end{array}$ & $\begin{array}{l}\text { Non-random } \\
\text { purposive } \\
\text { Interview } \\
\text { schedule } \\
6 \text { individuals } \\
1 \times 45 \text {-minute } \\
\text { interview and } \\
1 \times 15 \text {-minute } \\
\text { interview at a } \\
\text { later date }\end{array}$ & $\begin{array}{l}\text { I need to learn more; You really } \\
\text { have to seek them; Desperate } \\
\text { to get out; The little bit you } \\
\text { need; It is important to give } \\
\text { choice; Ticking up the pay } \\
\text { scale; Going up the ladder }\end{array}$ & $\begin{array}{l}\text { - Single author/researcher } \\
\text { - Ethical approval } \\
\text { - Questionable if truly 'newly' qualified } \\
\text { - Minimal demographics; gender split not } \\
\text { representative } \\
\text { - Small sample; unclear why didn't use all } 11 \\
\text { respondents } \\
\text { - Time lag between interviews unclear } \\
\text { - Purpose of } 2 \text { interviews unclear } \\
\text { - Unclear what 'prepared for interview' means } \\
\text { - Thick quotes linked to participants } \\
\text { - Themes titles unclear } \\
\text { - Did not identify any limitations }\end{array}$ \\
\hline $\begin{array}{l}\text { Gould } \\
\text { et al }\end{array}$ & $\begin{array}{l}\text { To explore qualified } \\
\text { nurses' experiences } \\
\text { of CPD; to explore } \\
\text { the relationship }\end{array}$ & $\begin{array}{l}\text { Qualitative, } \\
\text { descriptive and } \\
\text { quantitative }\end{array}$ & $\begin{array}{l}\text { Three contrasting, } \\
\text { acute NHS trusts in } \\
\text { London, England }\end{array}$ & $\begin{array}{l}\text { Random } \\
451(64.9 \%) \\
\text { questionnaires }\end{array}$ & $\begin{array}{l}\text { Who and what is CPD for?; } \\
\text { Accessing CPD; One size does } \\
\text { not fit all; Managing work, life } \\
\text { and doing CPD; Making the }\end{array}$ & $\begin{array}{l}\text { - Part of larger study, team methodology } \\
\text { - Ethical approval }\end{array}$ \\
\hline
\end{tabular}


(2007) / between CPD

nurses in standard

et al and extended roles

(2009) and their levels of

organisational
Hogston To understand what Qualitative
(1995) impact nurses
grounded
have on the quality of
nursing care
theory

Large hospital;

south of England

Volunteers sought

through

advertisement

Trust

Tame Exploring and

(2009) describing

Descriptive

, qualitative

(2011) lived experiences of

(2012) continuing

professional

education and

participation

$10 \%$ sample of

identified from the

payroll

Large teaching

NHS Trust;

north of England

Perioperative

nurses; currently
$125(27.7 \%)$

(

provided detalec

response to the

purposive

23 individuals

In-depth,

egistered on unstructured

undertaking [CPD] face inal face-to-

or who had

completed within

the previous 3

months
Less clear question and methods, including inclusion criteria

- Broad population, larger sample; only

- Qumpled 10\% or population

- Questionnaire included but crucial 'open

question unclear

- Possibly reflexive response to unexpected

high response rate

- Good demographics

- Thin quotes, not linked to participants

- Limitations acknowledged

New horizons; the professional - Unclear researcher

nurse; sanction and conviction - Ethical approval unclear

- Acknowledged work patterns affected ability

to interview nurses

- Minimal demographics

- Thick quotes linked to participants

- Minimal consideration of limitations

\section{- Single researcher}

[CPD] within perioperative

practice; negotiating the [CPD] - Ethical approval

- Greater methodology, analysis, limitations

and quotes as thesis utilised

- Thesis includes detailed analysis - textual and diagramatical

ints and finding

- Good demographics

- Identifies theoretical saturatio

- Acknowledges limitations including inability to interview nurses who do not participate in [CPD] 
Table 3: Factors influencing CPD

\begin{tabular}{|c|c|c|c|c|c|c|}
\hline Finding & $\begin{array}{l}\text { Synthesised } \\
\text { finding }\end{array}$ & $\begin{array}{c}\text { Bahn } \\
(2007 a) \\
(2007 b)\end{array}$ & $\begin{array}{c}\text { Balls } \\
(2010)\end{array}$ & $\begin{array}{c}\text { Gould et } \\
\text { al (2007) / } \\
\text { Drey et al } \\
(2009)\end{array}$ & $\begin{array}{c}\text { Hogston } \\
\text { (1995) }\end{array}$ & $\begin{array}{l}\text { Tame } \\
(2009) \\
(2011) \\
(2012)\end{array}$ \\
\hline $\begin{array}{l}\text { Individual's need to maintain/develop } \\
\text { skills }\end{array}$ & $\begin{array}{l}\text { Individual } \\
\text { resources }\end{array}$ & $\checkmark$ & $\checkmark$ & $\checkmark$ & $\checkmark$ & $\checkmark$ \\
\hline Individual's motivation to develop & & $\checkmark$ & $\checkmark$ & $\checkmark$ & $\checkmark$ & $\checkmark$ \\
\hline Individual's age / career stage & & $\checkmark$ & - & $\checkmark$ & - & $\checkmark$ \\
\hline Perceived relevance by individual & & $\checkmark$ & $\checkmark$ & $\checkmark$ & $\checkmark$ & $\checkmark$ \\
\hline CPD facilitating career progression & & $\checkmark$ & $\checkmark$ & $\checkmark$ & $\checkmark$ & $\checkmark$ \\
\hline Personal / family commitments & & $\checkmark$ & $\checkmark$ & $\checkmark$ & - & $\checkmark$ \\
\hline Funding & & $\checkmark$ & $\checkmark$ & - & $\checkmark$ & $\checkmark$ \\
\hline Part-time hours & & $\checkmark$ & - & $\checkmark$ & - & - \\
\hline Shift patterns / shift flexibility & & - & $\checkmark$ & $\checkmark$ & - & - \\
\hline Time for study & & $\checkmark$ & $\checkmark$ & $\checkmark$ & - & $\checkmark$ \\
\hline Previous CPD experiences & & $\checkmark$ & $\checkmark$ & - & - & $\checkmark$ \\
\hline Appraisal / development plan & & $\checkmark$ & $\checkmark$ & - & - & $\checkmark$ \\
\hline Mode of delivery & & - & - & $\checkmark$ & - & - \\
\hline Effect on self-confidence / self-worth & & $\checkmark$ & $\checkmark$ & $\checkmark$ & $\checkmark$ & $\checkmark$ \\
\hline Specific Higher Education factors & & $\checkmark$ & - & $\checkmark$ & - & $\checkmark$ \\
\hline Professional standards & Professional & $\checkmark$ & - & $\checkmark$ & $\checkmark$ & $\checkmark$ \\
\hline Care / service provision standards & motivation & $\checkmark$ & $\checkmark$ & $\checkmark$ & $\checkmark$ & $\checkmark$ \\
\hline Concern of loss of traditional roles & & $\checkmark$ & - & $\checkmark$ & - & $\checkmark$ \\
\hline Ability to extend roles & & $\checkmark$ & - & $\checkmark$ & - & $\checkmark$ \\
\hline Ability to question care & & $\checkmark$ & - & - & $\checkmark$ & $\checkmark$ \\
\hline Organisational standards & Organisational & $\checkmark$ & - & $\checkmark$ & - & $\checkmark$ \\
\hline Organisational / unit culture & commitment & $\checkmark$ & $\checkmark$ & $\checkmark$ & $\checkmark$ & $\checkmark$ \\
\hline Benefits to wider team & and & $\checkmark$ & - & $\checkmark$ & $\checkmark$ & $\checkmark$ \\
\hline Awareness / visibility of CPD & development & - & $\checkmark$ & $\checkmark$ & - & - \\
\hline Staffing levels & & $\checkmark$ & - & $\checkmark$ & - & $\checkmark$ \\
\hline Parity of CPD allocation & & $\checkmark$ & $\checkmark$ & $\checkmark$ & $\checkmark$ & $\checkmark$ \\
\hline Effect on working relationships & & $\checkmark$ & $\checkmark$ & - & $\checkmark$ & $\checkmark$ \\
\hline Effect on recruitment and retention & & - & $\checkmark$ & $\checkmark$ & - & $\checkmark$ \\
\hline Transferability of CPD & & - & $\checkmark$ & - & - & - \\
\hline Manager support & Managerial & $\checkmark$ & $\checkmark$ & $\checkmark$ & $\checkmark$ & $\checkmark$ \\
\hline Managers engaged with CPD & support & $\checkmark$ & - & - & - & $\checkmark$ \\
\hline $\mathrm{CPD}$ used negatively by managers & & - & - & $\checkmark$ & - & $\checkmark$ \\
\hline CPD as a 'reward' & & - & - & $\checkmark$ & $\checkmark$ & $\checkmark$ \\
\hline CPD to motivate staff & & - & - & $\checkmark$ & $\checkmark$ & - \\
\hline $\begin{array}{l}\text { Perceived relevance by workplace / } \\
\text { manager }\end{array}$ & & $\checkmark$ & - & - & $\checkmark$ & $\checkmark$ \\
\hline
\end{tabular}

Legend: ' $\checkmark$ ' considered; '-' not considered 
Table 4: CERQual summary of findings

Objective: To identify factors which influence hospital-based nurses' engagement with CPD through consideration of their attitudes, beliefs, opinions, views, perceptions, perspectives, experiences and / or engagement

\begin{tabular}{|c|c|c|c|}
\hline $\begin{array}{l}\text { Summary of review } \\
\text { finding }\end{array}$ & $\begin{array}{l}\text { Studies } \\
\text { contributing } \\
\text { to finding }\end{array}$ & $\begin{array}{l}\text { Assessment of } \\
\text { confidence in } \\
\text { the evidence }\end{array}$ & $\begin{array}{l}\text { Explanation of CERQual } \\
\text { assessment }\end{array}$ \\
\hline $\begin{array}{l}\text { Professional motivation, } \\
\text { enabling nurses to impact } \\
\text { care, influences CPD } \\
\text { engagement }\end{array}$ & All & $\begin{array}{l}\text { Moderate } \\
\text { confidence }\end{array}$ & $\begin{array}{l}\text { Minor concerns regarding } \\
\text { methodology, coherence and } \\
\text { relevance; moderate concerns } \\
\text { regarding adequacy }\end{array}$ \\
\hline $\begin{array}{l}\text { Organisational commitment } \\
\text { and managerial support } \\
\text { affect the value placed on } \\
\text { CPD and thus, influences } \\
\text { CPD engagement }\end{array}$ & All & $\begin{array}{l}\text { High } \\
\text { confidence }\end{array}$ & $\begin{array}{l}\text { No or very minor concerns } \\
\text { regarding coherence; minor } \\
\text { concerns re methodology, } \\
\text { adequacy and relevance }\end{array}$ \\
\hline $\begin{array}{l}\text { Individuals must weigh up } \\
\text { professional, organisational } \\
\text { and managerial influences } \\
\text { against their own resources } \\
\text { when considering initial or } \\
\text { continual engagement with }\end{array}$ & All & $\begin{array}{l}\text { Moderate } \\
\text { confidence }\end{array}$ & $\begin{array}{l}\text { No or very minor concerns } \\
\text { regarding coherence; minor } \\
\text { concerns regarding adequacy } \\
\text { and relevance; moderate } \\
\text { concerns regarding } \\
\text { methodology }\end{array}$ \\
\hline
\end{tabular}

Footnote: (Lewin et al, 2018) 